\title{
A POLÍTICA NACIONAL DE PROTEÇÃO E DEFESA CIVIL E A BUSCA PELA SUSTENTABILIDADE NAS ÁREAS VULNERÁVEIS DOS CENTROS URBANOS
}

\author{
LA POLÍTICA NACIONAL PARA LA PROTECCIÓN Y DEFENSA CIVIL Y LA \\ BÚSQUEDA DE LA SOSTENIBILIDAD EN LAS ZONAS VULNERABLES DE LOS \\ CENTROS URBANOS
}

\author{
Henrique Rosmaninho Alves \\ Instituto Minas de Educação e Cultura-IMEC - Nanuque - Minas Gerais - Brasil \\ José Cláudio Junqueira Ribeiro \\ Escola Superior Dom Helder Câmara - Belo Horizonte - Minas Gerais - Brasil
}

\begin{abstract}
RESUMO:A existência de áreas especialmente sujeitas à ocorrência de desastres naturais nos centros urbanos é uma realidade no Brasil. Diante disso buscou-se estudar a Lei no 12.608/2012 que regulamenta a gestão de desastres naturais no País e a sua relação com a sustentabilidade das áreas de risco e dos centros urbanos. Para tanto, investigou-se os fatores responsáveis pela vulnerabilidade das áreas de risco, a atual magnitude dos desastres ocorridos no País e os contornos da vigente Política Nacional de Proteção e Defesa Civil. Realizou-se uma investigação jurídico-sociológica, visto que se partiu da análise do fenômeno socioambiental, relativamente à sua origem e abrangência, para posteriormente debruçar-se sobre $a$ Lei $\mathrm{n}^{\circ}$ 12.608/2012. Empregou-se um marco teórico que englobou a lei oㅜ $12.608 / 2012$, os dados obtidos pelos órgãos de educação e de Defesa Civil do País e a concepção de desenvolvimento sustentável do Relatório Brundtland. Ao final, conclui-se que a PNPDEC visa promover a sustentabilidade das áreas de risco, por meio de medidas ambientais, econômicas e sociais, porém em casos extremos, o reconhecimento da insustentabilidade de certas localidades enseja a realocação da população, o que se coaduna com o objetivo de construção de cidades resilientes e sustentáveis.
\end{abstract}

Palavras-chave: Sustentabilidade; Desastres naturais; Áreas de risco.

RESUMEN: La existencia de zonas especialmente propensas a la ocurrencia de desastres naturales en los centros urbanos es una realidad en Brasil. Delante tal escenario se estudió la Ley no 12.608/2012, que regula la gestión de los desastres naturales en el País y sus relaciones con la sostenibilidad de las zonas de riesgo y de los centros urbanos. Con este fin, se investigó los factores responsables por la vulnerabilidad de las zonas de alto riesgo, la actual magnitud de los desastres en el País y los contornos de la actual Política Nacional de Protección y Defensa Civil. Se realizó una investigación jurídica y sociológica, que empezó con el análisis del fenómeno socioambiental, relativamente a su origen y alcance, para después estudiar la Ley $n^{\circ} 12.608 / 2012$. Se utilizó de un marco teórico que incluye la Ley $n^{\circ}$

Revista do Direito da UNISC, Santa Cruz do Sul, v..2, n. 46, p. 63-85, maio - ago. 2015. 
12.608/2012, los datos obtenidos por los órganos de educación y defensa civil del País y la concepción de desarrollo sostenible del Informe Brundtland. Al final, se concluye que la PNPDEC tiene como objetivo promover la sostenibilidad en las áreas de riesgo a través de medidas ambientales, económicas y sociales, pero en casos extremos, el reconocimiento de la insostenibilidad de determinadas localidades, que implica la reubicación de la población, se coaduna con el objetivo de construir ciudades resilientes y sostenibles.

Palabras-clave: Sostenibilidad; Desastres naturales; Zonas de riesgo.

\section{INTRODUÇÃO}

A gestão de desastres naturais promovida no Brasil é regulamentada primordialmente pela Lei no 12.608/2012, norma vulgarmente conhecida como Política Nacional de Proteção e Defesa Civil.

Referida norma versa sobre diversos temas como urbanização, proteção do meio ambiente natural, medidas de prevenção e resposta a desastres, meios de participação popular, obrigações dos entes federados na execução da gestão de desastres naturais, entre outras.

Busca-se então analisar a Lei no 12.608/2012 como um todo, sob a perspectiva da sustentabilidade, visando identificar se tal norma objetiva construir a sustentabilidade nas áreas de risco.

Recentemente a incidência de desastres naturais no País vem crescendo consideravelmente, provocando milhares de mortes e outros prejuízos materiais que afetaram principalmente a população detentora de menor poder aquisitivo. Em decorrência desse cenário, a necessidade de evitar a reincidência desses eventos e de capacitar as comunidades para o enfrentamento de fenômenos naturais intensos, promovendo se possível a sustentabilidade das áreas de risco, torna-se um tema de extrema relevância que merece a atenção dos estudiosos.

No decorrer dos estudos, realizou-se uma investigação jurídico-sociológica, buscando compreender as origens dos fenômenos sociais (criação de áreas de risco e ocorrência de desastres naturais), a sua atual abrangência e formatação (tipos de desastres naturais mais recorrentes e quantidade de danos causados), para proceder a uma análise do fenômeno jurídico visando identificar os principais objetivos da PNPDEC e compreender como funcionam as atividades de gestão de

Revista do Direito da UNISC, Santa Cruz do Sul, v..2, n. 46, p. 63-85, maio - ago. 2015. 
desastres do país, com vistas à redução, prevenção e resposta aos danos provocados pelo impacto de fenômenos naturais.

Apresenta-se como marco teórico a Lei oㅜ 12.608/2012, os dados obtidos pelos órgãos de educação e de Defesa Civil e a concepção de desenvolvimento sustentável do Relatório Brundtland. Utiliza-se também dos estudos de Delton Winter de Carvalho e Fernanda Dalla Libera Damacena e de José Eli da Veiga acerca da gestão de desastres e do desenvolvimento humano, respectivamente.

O conteúdo da investigação foi dividido em 3 capítulos, destinados respectivamente a demonstrar o que são desastres naturais e quais são as modalidades mais recorrentes no Brasil; qual o significado da expressão sustentabilidade e sua relação com as áreas de risco e; como a PNPDEC atua com vistas a reduzir a insustentabilidade dos centros urbanos.

Acredita-se que o estudo desenvolvido pode contribuir para os estudos acadêmicos pátrios por versar sobre questão ainda pouco abordada nas universidades, e indiretamente à própria gestão de desastres nacional, visto que a investigação pode incentivar novas pesquisas que apontem alternativas mais eficazes na redução de riscos e mitigação de danos.

\section{OS DESASTRES NATURAIS NO BRASIL}

Os desastres naturais são responsáveis anualmente por consideráveis prejuízos a humanidade que se subdividem em danos patrimoniais (destruição de residências por deslizamentos, por ex.) e extrapatrimoniais (óbitos, enfermidades, ferimentos leves e graves, por ex.).

A elevação da incidência de desastre naturais em todo o planeta fez com que o Programa das Nações Unidas para o Desenvolvimento - PNUD os elencasse no Relatório de Desenvolvimento Humano 2014 como uma das seis principais ameaças ao desenvolvimento.

No Brasil o Decreto 7.257/2010 definiu desastres em seu artigo 2ํㅡㄹ inciso II, como "resultado de eventos adversos, naturais ou provocados pelo homem sobre um ecossistema vulnerável, causando danos humanos, materiais ou ambientais e consequentes prejuízos econômicos e sociais". (BRASIL, 2010)

Revista do Direito da UNISC, Santa Cruz do Sul, v..2, n. 46, p. 63-85, maio - ago. 2015. 
O Instituto Nacional de Pesquisas Espaciais - INPE conceituou desastres naturais como "o resultado de eventos adversos que causam grandes impactos na sociedade [...] são causados pelo impacto de um fenômeno natural de grande intensidade sobre uma área ou região povoada, podendo ou não ser agravado pelas atividades antrópicas". (BRASIL, 2007, p.5)

O Ministério da Integração, na Política Nacional de Defesa Civil de 2007 determinou que os desastres naturais "são aqueles provocados por fenômenos e desequilíbrios da natureza. São produzidos por fatores de origem externa que atuam independentemente da ação humana." (BRASÍLIA, 2007)

Diversos fenômenos naturais podem ser responsáveis por impactos que resultem em danos materiais, humanos e ambientais, como as enchentes, terremotos, avalanches, seca, deslizamentos de terra, tsunamis, furacões, erupções vulcânicas, vendavais, entre outros.

O Instituto Nacional de Pesquisas Espaciais catalogou os tipos de fenômenos naturais mais recorrentes em todos os continentes e no Brasil:

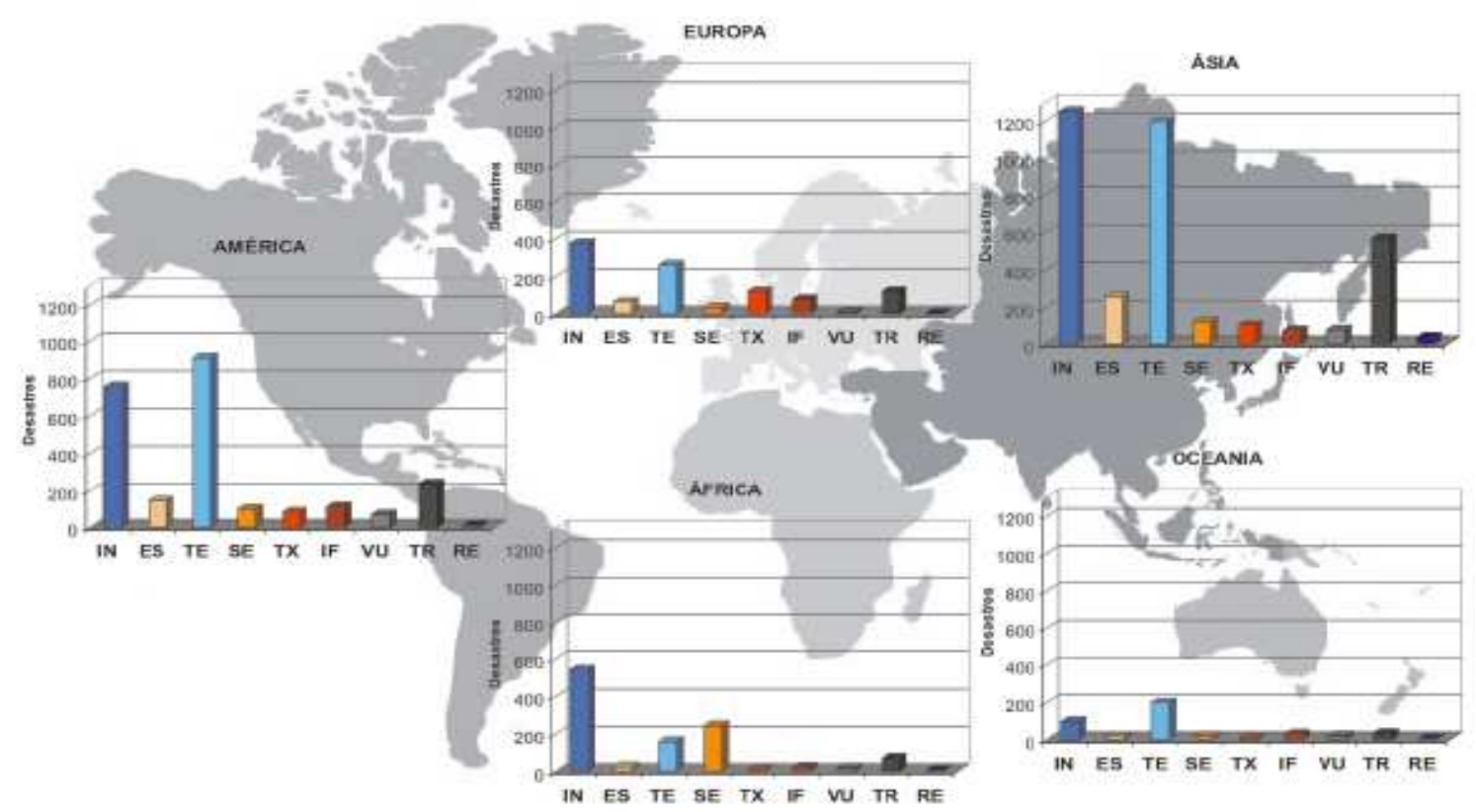

Gráfico 1 - Distribuição por continente dos desastres naturais ocorridos no globo (1900-2006)

Legenda: IN - inundação, ES - escorregamento, TE - tempestade, SE seca, TX - temperatura extrema, IF - incêndio florestal, VU - vulcanismo, TR - terremoto e RE - ressaca.

Fonte: (BRASIL, 2007, p.7)

Revista do Direito da UNISC, Santa Cruz do Sul, v..2, n. 46, p. 63-85, maio - ago. 2015. 


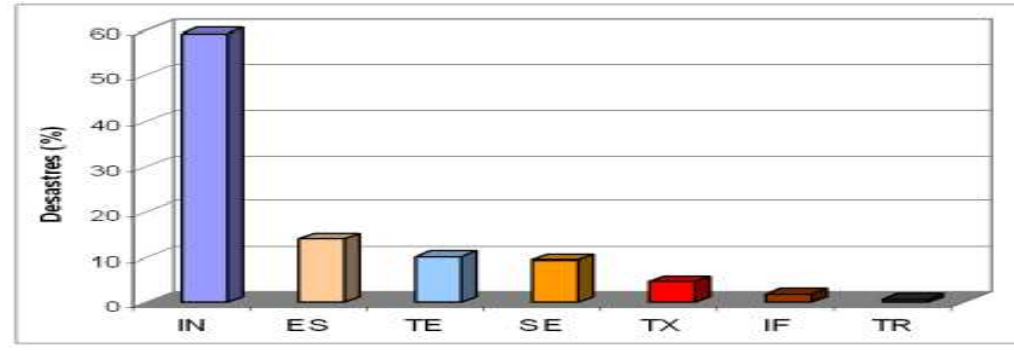

Gráfico 2 - Tipos de Desastres Naturais ocorridos no Brasil (1900-2006)

Legenda: IN - inundação, ES - escorregamento, TE - tempestade, SE seca,

TX - temperatura extrema, IF - incêndio florestal, TR - terremoto.

Fonte: (BRASIL, 2007, p.8)

Percebe-se pela leitura do gráfico 2 que as inundações, escorregamentos de terra e tempestades são os eventos naturais responsáveis por desastres mais recorrentes no Brasil.

Os fenômenos naturais devido à sua força e imprevisibilidade (muito mitigada pelo avanço tecnológico) possuem grande poder de destruição, ocasionando os mais variados danos à população.

O Ministério da Integração, por intermédio do Centro Nacional de Gerenciamento de Riscos e Desastres elaborou o Anuário Brasileiro de Desastres Naturais relativos aos anos de 2011 e 2012, em que se verificaram quais são os fenômenos naturais responsáveis pelos maiores danos à população brasileira.

\begin{tabular}{|c|c|c|c|c|c|c|c|c|}
\hline Eventos & Óbitos & Feridos & Enfermos & Desabrigados & Desalojados & Desaparecidos & Afetados & $\begin{array}{l}\text { Quantidade } \\
\text { de Municipios } \\
\text { Afetados }\end{array}$ \\
\hline Enxurradas & 518 & 304 & 306 & 52.832 & 247.726 & 2 & 7.043 .989 & 944 \\
\hline Inundação & 79 & 195 & 104 & 49.644 & 315.885 & 0 & 2.050 .431 & 515 \\
\hline Seca & 3 & 10 & 9.553 & 10 & 76 & 0 & 1.308 .873 & 234 \\
\hline Vendaval & 16 & 108 & 30 & 1.742 & 12.812 & 0 & 900.309 & 236 \\
\hline Deslizamentos & 472 & 11 & 0 & 7.228 & 44.519 & 0 & 676.388 & 161 \\
\hline Granizo & 0 & 33 & 2 & 938 & 20.632 & 0 & 214.461 & 130 \\
\hline Alagamentos & 1 & 11 & 0 & 2.874 & 13.287 & 3 & 179.133 & 92 \\
\hline Erosāo & 0 & 0 & 0 & 0 & 190 & 0 & 92.508 & 25 \\
\hline Chuvas Intensas & 2 & 0 & 0 & 271 & 649 & 0 & 27.036 & 21 \\
\hline Ressaca & 0 & 0 & 2 & 0 & 176 & 0 & 21.268 & 5 \\
\hline Friagem & 2 & 0 & 564 & 0 & 0 & 0 & 20.004 & 4 \\
\hline Geada & 0 & 0 & 0 & 0 & 0 & 0 & 1.000 & 2 \\
\hline $\begin{array}{l}\text { Tempestades } \\
\text { de Raios }\end{array}$ & 1 & 0 & 0 & 0 & 0 & 0 & 1 & 1 \\
\hline Total & 1.094 & 672 & 10.561 & 115.539 & 655.952 & 5 & 12.535 .401 & 2.370 \\
\hline
\end{tabular}

Tabela 1: Danos Humanos por Tipo de Evento de Desastre - 2011

Fonte: (BRASIL, 2012, p.33)

Revista do Direito da UNISC, Santa Cruz do Sul, v..2, n. 46, p. 63-85, maio - ago. 2015. 


\begin{tabular}{|c|c|c|c|c|c|c|c|}
\hline EVENTOS & Óbitos & Feridos & Enfermos & Desabrigados & Desalojados & Desaparecidos & Afetados \\
\hline Seca/Estiagem & 6 & 0 & 14.214 & 30 & 750 & 0 & 8.956 .853 \\
\hline $\begin{array}{c}\text { Incêndio } \\
\text { Florestal }\end{array}$ & 0 & 0 & 0 & 0 & 0 & 0 & 37.338 \\
\hline $\begin{array}{c}\text { Movimentos } \\
\text { de massa }\end{array}$ & 26 & 10 & 2 & 1.129 & 2.801 & 0 & 123.555 \\
\hline Erosão & 0 & 0 & 5 & 81 & 2.105 & 0 & 55.653 \\
\hline Alagamentos & 5 & 6 & 6 & 1.048 & 954 & 0 & 24.581 \\
\hline Enxurradas & 26 & 6.580 & 14.318 & 49.769 & 262.851 & 2 & 1.856 .359 \\
\hline Inundações & 14 & 2.409 & 10.665 & 52.041 & 216.349 & 2 & 5.185 .018 \\
\hline Geadas & 0 & 0 & 0 & 0 & 0 & 0 & 30.777 \\
\hline Granizo & 0 & 11 & 4 & 418 & 7.971 & 1.040 & 103.265 \\
\hline Tornados & 0 & 2 & 0 & 1 & 20 & 0 & 4.310 \\
\hline Vendaval & 16 & 150 & 13 & 5.769 & 13.220 & 0 & 599.905 \\
\hline TOTAL & 93 & 9.168 & 39.227 & 110.286 & 507.021 & 1.044 & 16.977 .614 \\
\hline
\end{tabular}

Tabela 2: Danos Humanos por tipo de Evento de Desastre - 2012

Fonte: (BRASIL, 2013, p.33)

Nota-se pela análise das tabelas dos Anuários Brasileiros de Desastres Naturais de 2011 e de 2012 que os fenômenos naturais causadores de maiores danos à sociedade são as inundações, enxurradas e deslizamentos de terra/movimentos de massa. Apenas no que tange aos óbitos e aos desabrigados, no biênio 2011/2012 as inundações foram responsáveis por 93 óbitos e 101.685 desabrigados, as enxurradas foram responsáveis por 544 óbitos e 101.601 desabrigados e os deslizamentos de terra/movimentos de massa foram responsáveis por 498 óbitos e 8.357 desabrigados.

Há que se mencionar que os danos provocados por fenômenos naturais são potencializados por alguns fatores antrópicos, que aumentam a vulnerabilidade de um determinado local ou comunidade aos impactos resultantes dos mesmos.

Delton Winter de Carvalho e Fernanda Dalla Libera Damacena citam 5 fatores de potencialização dos riscos e custos dos desastres na sociedade contemporânea, quais sejam: condições econômicas modernas; mudanças climáticas; destruição de infraestrutura verde e construída; crescimento populacional e tendência demográfica; e decisões acerca da ocupação do solo. (CARVALHO; DAMACENA, 2013) Em estudo denominado "Mapa mental das enchentes urbanas" a Universidade Federal Rural do Rio de Janeiro - UFRRJ identificou como os maiores responsáveis por tais fenômenos a impermeabilização do solo e a disposição inadequada de resíduos sólidos, o que se encaixa na destruição da infraestrutura verde, citada por Carvalho e Damascena. (UFRRJ, 2014)

Revista do Direito da UNISC, Santa Cruz do Sul, v..2, n. 46, p. 63-85, maio - ago. 2015. 
É notório que a destruição das infraestruturas verdes e construídas, as mudanças climáticas e as decisões acerca da ocupação do solo são matérias de nítido caráter ambiental (destruição das infraestruturas verdes e mudanças climáticas) e urbanístico (destruição das infraestruturas construídas e decisões acerca da ocupação do solo) que influenciam diretamente a sustentabilidade do meio ambiente humano (urbano e rural).

\section{SUSTENTABILIDADE E ÁREAS DE RISCO}

A sustentabilidade é uma noção derivada do desenvolvimento sustentável que possui um conceito amplo e consideravelmente variável, conforme a posição de quem o analisa relativamente ao tempo e ao espaço.

O Relatório Brundtland publicado em 1987 definiu o desenvolvimento sustentável como:

O desenvolvimento que procura satisfazer as necessidades da geração atual, sem comprometer a capacidade das gerações futuras de satisfazerem as suas próprias necessidades, significa possibilitar que as pessoas, agora e no futuro, atinjam um nível satisfatório de desenvolvimento social e econômico e de realização humana e cultural, fazendo, ao mesmo tempo, um uso razoável dos recursos da terra e preservando as espécies e os habitats naturais. (Relatório Brundtland, 1987)

O desenvolvimento, na perspectiva do Relatório Brundtland não se restringe apenas ao crescimento econômico, mas à elevação da qualidade de vida em consonância com a preservação do meio ambiente para as futuras gerações.

Coaduna-se com a concepção de desenvolvimento de José Eli da Veiga na qual "o desenvolvimento tem a ver, primeiro e acima de tudo, com a possibilidade de as pessoas viverem o tipo de vida que escolheram, e com a provisão dos instrumentos e das oportunidades para fazerem as suas escolhas", em que o desenvolvimento não é visto apenas como crescimento econômico, mas como meio de se garantir a dignidade humana. (VEIGA, 2008, p.81)

A sustentabilidade é a capacidade que um sistema tem de se manter estável e perenizar-se ao longo do tempo, mantendo suas características. Aplicada ao

Revista do Direito da UNISC, Santa Cruz do Sul, v..2, n. 46, p. 63-85, maio-ago. 2015. 
cenário de desenvolvimento humano, pode-se dividi-la em três aspectos: ambiental, econômico e social.

A sustentabilidade ambiental refere-se à capacidade do meio ambiente promover condições saudáveis para a vida humana, inclusive às futuras gerações, sem comprometer a biodiversidade. A ideia de futuro é inerente ao conceito, o que se pode verificar, no caso em tela, na necessidade de manutenção das condições de vida saudável para as futuras gerações.

No aspecto econômico a sustentabilidade concerne à capacidade de 0 sistema econômico possibilitar o acesso ao emprego e a renda de modo que se universalize um padrão de consumo suficiente para proporcionar a busca do ideal de vida boa. A dignidade humana ganha grande notoriedade na sustentabilidade econômica, ao passo que o consumo é indispensável para proporcionar a autonomia e o mínimo existencial, indispensável a todos os seres humanos que almejem uma vida digna.

Por fim, quanto ao aspecto social, a sustentabilidade designa a modalidade de exercício do poder instituído e o modo como ocorrem as relações interpessoais. A igualdade entre as pessoas e a liberdade para buscar o ideal de vida boa sem adentrar na esfera da liberdade de outrem são pilares da sustentabilidade social. $O$ modo como transcorrem as relações sociais deve ser capaz de proporcionar a busca pelo ideal de vida boa, visto que se não o for, a sociedade pode entrar em colapso com a emergência de revoluções sociais que objetivarão a mudança do exercício do poder instituído e do modo como as pessoas se relacionam.

\section{1 Áreas de risco}

Na sociedade contemporânea brasileira em todo o território nacional existem pessoas que habitam em áreas potencialmente sujeitas à ocorrência de desastres naturais, um cenário especialmente insustentável sobre diversos aspectos.

O Plano Diretor de Belo Horizonte em seu artigo 28 define as áreas de risco geológico:

Art. 28 - As áreas de risco geológico são as sujeitas a sediar evento geológico natural ou induzido ou a serem por ele atingidas, dividindo-se nas seguintes categorias de risco:

Revista do Direito da UNISC, Santa Cruz do Sul, v..2, n. 46, p. 63-85, maio - ago. 2015. 
I - potencial, incidente em áreas não parceladas e desocupadas;

II - efetivo, incidente em áreas parceladas ou ocupadas.

$\S 1^{\circ}$ - São as seguintes as modalidades de risco geológico:

I - de escorregamento;

II - associado a escavações;

III - de inundações;

IV - de erosão e assoreamento;

V - de contaminação do lençol freático (Belo Horizonte, 2013).

As áreas de risco, como são conhecidos os locais vulneráveis a ocorrência de desastres naturais, têm características peculiares relativas a aspectos ambientais e socioeconômicos.

No que tange ao aspecto socioeconômico, geralmente tais áreas são habitadas por populações de baixa renda, o que pode-se explicar pela observação do processo de urbanização ocorrido no Brasil ao longo do século XX.

A urbanização brasileira ocorreu de maneira célere e concomitante a uma explosão demográfica que contribuiu para a ausência de planejamento e culminou na ocupação desordenada do território urbano.

\begin{tabular}{|l|l|l|l|l|l|}
\hline $\begin{array}{l}\text { Ano do } \\
\text { Censo }\end{array}$ & Populaçăo Total & $\begin{array}{l}\text { População } \\
\text { Urbana }\end{array}$ & $\begin{array}{l}\text { Indice de } \\
\text { Urbanizaçăo }\end{array}$ & $\begin{array}{l}\text { Indice de } \\
\text { crescimento } \\
\text { Populacional }\end{array}$ & $\begin{array}{l}\text { Indice } \\
\text { crescimento } \\
\text { Urbano }\end{array}$ \\
\hline 1900 & 17.438 .434 & - & - & - & - \\
\hline 1920 & 27500.000 & 4552.000 & $16,55 \%$ & $43,08 \%$ & - \\
\hline 1940 & 41.326 .000 & 10.891 .000 & $26,35 \%$ & $33,46 \%$ & $37,19 \%$ \\
\hline 1950 & 51.944 .000 & 18.783 .000 & $36,16 \%$ & $25,70 \%$ & $72,46 \%$ \\
\hline 1960 & 70.191000 & 31.956 .000 & $45,52 \%$ & $35,13 \%$ & $70,13 \%$ \\
\hline 1970 & 93.139000 & 52.905 .000 & $56,80 \%$ & $32,69 \%$ & $65,55 \%$ \\
\hline 1980 & 119.099 .000 & 82.013 .000 & $68,86 \%$ & $27,87 \%$ & $55,02 \%$ \\
\hline 1991 & 150.400 .000 & 110.990 .990 & $73,80 \%$ & $26,28 \%$ & $35,33 \%$ \\
\hline 2000 & 169.799 .70 & 145.800 .000 & $85,87 \%$ & $12,90 \%$ & $31,36 \%$ \\
\hline 2006 & 186.119 .238 & 165.832 .920 & $89,10 \%$ & $9,61 \%$ & $13,74 \%$ \\
\hline
\end{tabular}

Tabela 3 - População total e urbana no Brasil

Fontes: Cadernos Mcidades/Des. Urbano Política Nacional de Desenvolvimento Urbano 1, Brasília, Novembro de 2004; Ruben George Oliven, Urbanização e mudança social no Brasil, Vozes, Petrópolis, 1980, p. 69, tabela 1; IBGE, Censos de 1940-2000/ estimativa maio/2006.

Em 40 anos a população urbana brasileira cresceu $750 \%$ e consequentemente as cidades expandiram-se para acomodar esse excedente populacional.

Durante 0 processo de crescimento das cidades predominaram ordenamentos jurídicos urbanísticos e políticas públicas elitistas que desconsideravam, ao estabelecer as normas de uso e ocupação do solo, a classe operária que não possuía condições financeiras de adquirir um imóvel no centro e nos bairros ao seu redor. (SERRANO JUNIOR, 2012)

Revista do Direito da UNISC, Santa Cruz do Sul, v..2, n. 46, p. 63-85, maio - ago. 2015. 
Afastados por suas condições econômicas da cidade regular, dotada de equipamentos urbanos (água, energia elétrica, saneamento básico, pavimentação), a população carente acomodou-se em invasões e ocupações irregulares em sua maioria distantes da cidade regular, o que culminou na favelização dos centros urbanos e na distinção entre a "cidade dos ricos" e a "cidade dos pobres". (NOLASCO, 2008)

Luiz Paulo Conde aduz que ao se encontrar sem moradia, "o brasileiro foi buscar nas favelas e nas construções clandestinas a solução de seus problemas de moradia", sendo que "a ausência do poder público, extremamente burocratizado e elitizado, contribuiu para estimular o processo de favelização das cidades". (CONDE, 1992, p.13-15)

Os assentamentos urbanos ocupados pela população de baixa renda não raras vezes localizavam-se em áreas ambientalmente impróprias para moradia, como encostas de morros, que devido à inclinação do terreno sujeitavam os moradores a deslizamentos de terra; margens de rios e córregos que no período chuvoso provocavam enxurradas e inundações.

À ocupação de áreas impróprias somava-se a ausência de infraestrutura urbana decorrente do abandono do poder público à "cidade irregular" e a precariedade das construções edificadas com materiais de baixa qualidade e sem a estruturação adequada.

A violência também é outra característica da urbanização desordenada, conforme indicam estudos de Luiz Cesar Queiroz Ribeiro. Segundo o autor, a segregação espacial entre ricos e pobres gera impactos corrosivos nas relações de reciprocidade entre grupos e classes sociais, sendo responsável pela reprodução da pobreza e pelo crescimento da criminalidade. (RIBEIRO, 2006)

Quanto ao aspecto ambiental, conforme já mencionado, as áreas de risco ordinariamente situam-se em locais ambientalmente vulneráveis às intempéries da natureza, como beiras de rios, encostas de morros, áreas de alagamento entre outras.

Delton Winter de Carvalho e Fernanda Dalla Libera Damacena elencam 5 fatores como os principais responsáveis pela ampliação dos riscos e custos dos desastres na sociedade contemporânea, quais sejam: condições econômicas 
modernas; crescimento populacional e tendências demográficas; decisões acerca da ocupação do solo; destruição das infraestruturas naturais e construídas; mudanças climáticas.

As decisões acerca da ocupação do solo e a destruição das infraestruturas naturais são fatores intimamente ligados à criação de áreas de risco.

Entende-se por infraestruturas naturais os elementos naturais do meio ambiente capazes de proteção contra desastres naturais em razão dos seus serviços ecossistêmicos. Podem-se citar como espécies de infraestrutura natural as dunas, vegetações rasteiras, florestas, matas ciliares, etc.

$\mathrm{Na}$ visão de Carvalho e Damascena esses elementos podem auxiliar de duas formas a atuação ante os desastres:

Primeiro, atuando como um bloqueio natural aos impactos de um desastre,
diminuindo ou desviando as forças da natureza da direção das
comunidades humanas. Ainda, após os impactos, esta servirá novamente
para prover bens e serviços de fundamental importância para a recuperação
econômica e física do local atingido. (CARVALHO, DAMASCENA, 2013,
p.50-51)

Os sistemas naturais são dotados de enorme potencial para a proteção das comunidades humanas, destacando-se no contexto nacional a manutenção de áreas permeáveis e a preservação das vegetações de topos de morros e encostas, visto que no Brasil os fenômenos naturais que mais provocam danos são os deslizamentos e enchentes. A impermeabilização do solo e a retirada da vegetação das encostas e dos topos de morros contribuem efetivamente para enchentes e deslizamentos.

A somatória da destruição das infraestruturas naturais e a ocupação desordenada do solo urbano deu origem às mencionadas áreas de risco, que contemporaneamente comportam milhares de pessoas.

Para se ter uma noção, apenas no Município de Betim um estudo realizado pelo Ministério das Minas e Energia em 2012 constatou a existência de 35 áreas de risco que abrigam mais de 10.000 pessoas, sujeitando-as à riscos de enchentes, deslizamentos de terra e inundações. (BRASIL, 2012)

Revista do Direito da UNISC, Santa Cruz do Sul, v..2, n. 46, p. 63-85, maio - ago. 2015. 


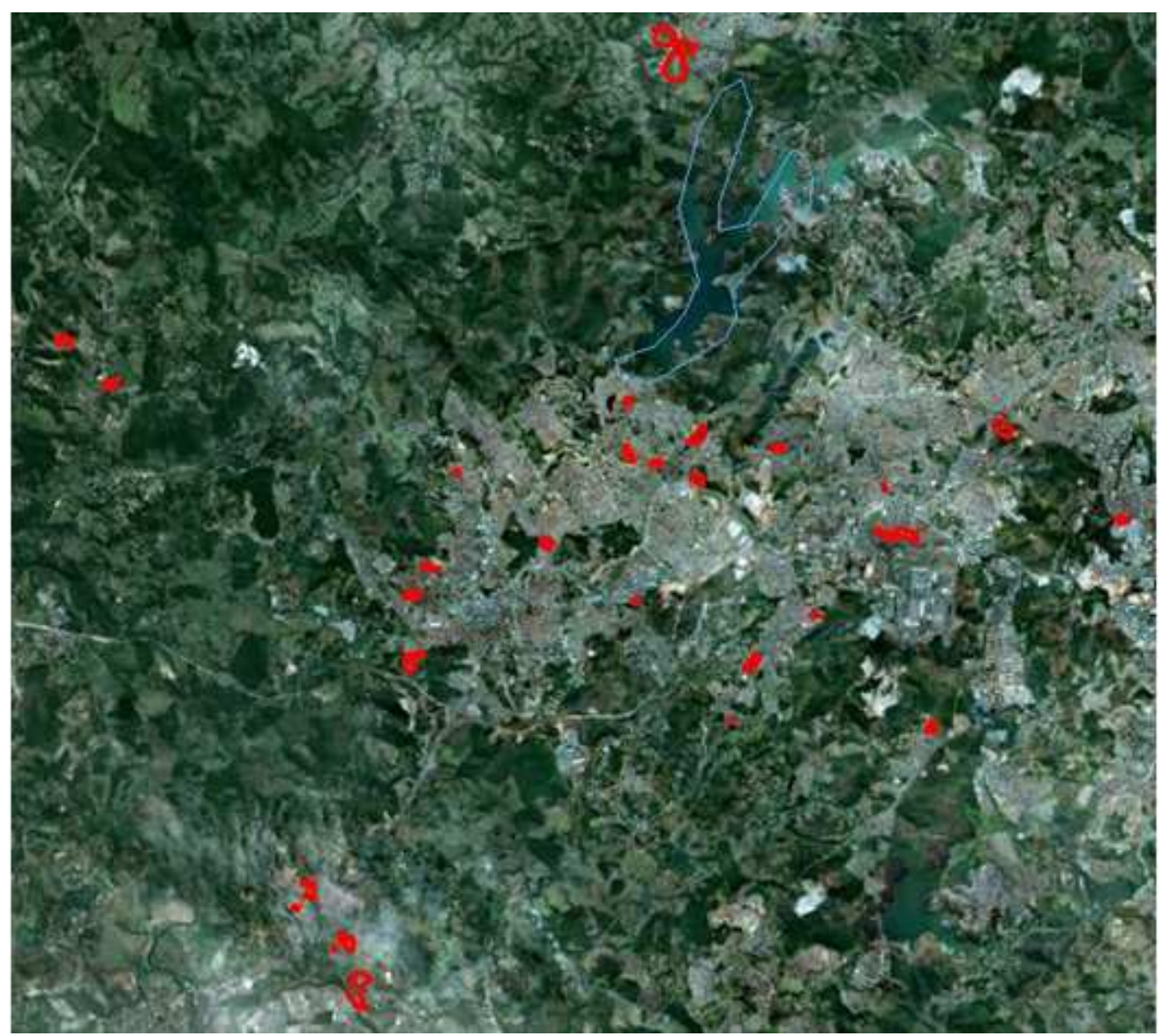

Figura 1 - Vista geral das áreas de risco alto e muito alto (vermelho) do Município de Betim/MG

Com a crescente concretização dos riscos nos últimos anos e o consequente aumento no número de danos materiais e humanos, no ano de 2012 foi sancionada a lei ㄲo 12.608/2012, conhecida como Política Nacional de Proteção e Defesa Civil PNPDEC - com vistas a mitigar futuros danos e organizar uma gestão apta a dirimir os riscos de desastres naturais.

A PNPDEC abrange as ações prevenção, mitigação, preparação, resposta e recuperação, priorizando, no entanto, as ações de prevenção. Referido diploma contém diversos dispositivos acerca das áreas de risco conforme se verificará a seguir.

\subsection{A PNPDEC e as áreas de risco}

A Lei no 12.608/2012 disciplinou a gestão das áreas de risco em todo o País, distribuindo competências entre os entes federativos com o objetivo de dirimir os riscos e danos provenientes de impactos de fenômenos naturais.

Revista do Direito da UNISC, Santa Cruz do Sul, v..2, n. 46, p. 63-85, maio-ago. 2015. 
O artigo 4ำ inseriu o "planejamento com base em pesquisas e estudos sobre áreas de risco e incidência de desastres no território nacional" como uma das diretrizes da PNPDEC, o que evidência a atenção ofertada a tais localidades. (BRASIL, 2012)

No que tange aos objetivos estabelecidos pela Lei 12.608/2012, ao menos quatro referem-se diretamente às áreas de risco, como a promoção da identificação e avaliação das ameaças, suscetibilidades e vulnerabilidades a desastres, de modo a evitar ou reduzir sua ocorrência; o estímulo ao adequado ordenamento da ocupação do solo urbano e rural, tendo em vista sua conservação e a proteção da vegetação nativa, dos recursos hídricos e da vida humana; o combate à ocupação de áreas ambientalmente vulneráveis e de risco e a promoção da realocação da população residente nessas áreas e; a recuperação das áreas afetadas por desastres.

Outros objetivos, mesmo que indiretamente, relacionam-se às áreas de risco, como o estímulo a iniciativas que resultem na destinação de moradia em local seguro e a incorporação da redução de riscos de desastres e das ações de proteção e defesa civil entre os elementos da gestão territorial e do planejamento das políticas setoriais.

A importância atribuída à gestão das áreas de risco foi tão grande que a PNPDEC distribuiu competências entre todos os entes da federação para a sua promoção.

À União compete o apoio aos Estados, ao Distrito Federal e aos Municípios no mapeamento das áreas de risco, nos estudos de identificação de ameaças, suscetibilidades, vulnerabilidades e risco de desastre e nas demais ações de prevenção, mitigação, preparação, resposta e recuperação; a instituição e manutenção de sistema de informações e monitoramento de desastres e do cadastro nacional de municípios com áreas suscetíveis à ocorrência de deslizamentos de grande impacto, inundações bruscas ou processos geológicos ou hidrológicos correlatos e; a realização do monitoramento meteorológico, hidrológico e geológico das áreas de risco, bem como dos riscos biológicos, nucleares e químicos, e a produção de alertas sobre a possibilidade de ocorrência de desastres, em articulação com os Estados, o Distrito Federal e os Municípios. (BRASIL, 2012) 
Salienta-se com relação às competências da União a instituição do sistema de informações e monitoramento de desastres, realizado pelo Centro Nacional de Monitoramento e Alerta de Desastres Naturais - CEMADEN - que possibilita o alerta antecipado às populações residentes em áreas vulneráveis, permitindo a evacuação dessas áreas, o que evita a concretização de maiores prejuízos materiais e humanos à sociedade.

No que concerne aos Estados, a sua atuação com relação às áreas de risco ficou restrita a identificar e mapear as áreas de risco e realizar estudos de identificação de ameaças, suscetibilidades e vulnerabilidades, em articulação com a União e os Municípios; realizar o monitoramento meteorológico, hidrológico e geológico das áreas de risco, em articulação com a União e os Municípios e; apoiar, sempre que necessário, os Municípios no levantamento das áreas de risco, na elaboração dos Planos de Contingência de Proteção e Defesa Civil e na divulgação de protocolos de prevenção e alerta e de ações emergenciais. (BRASIL, 2012)

Percebe-se que o legislador optou por deixar ao Estado o auxílio à União e aos Municípios no mapeamento, monitoramento e levantamento das áreas de risco. Referido apoio, no plano fático, é indispensável, diante da escassez de recursos financeiros dos Municípios para a realização de tais tarefas.

Os Municípios, por sua vez, foram os entes federativos dotados de maiores atribuições com relação às áreas de risco. Aos municípios foram delegadas as tarefas de identificar e mapear as áreas de risco de desastres; promover a fiscalização das áreas de risco de desastre e vedar novas ocupações nessas áreas; vistoriar edificações e áreas de risco e promover, quando for o caso, a intervenção preventiva e a evacuação da população das áreas de alto risco ou das edificações vulneráveis; manter a população informada sobre áreas de risco e ocorrência de eventos extremos, bem como sobre protocolos de prevenção e alerta e sobre as ações emergenciais em circunstâncias de desastres. (BRASIL, 2012)

Ressaltem-se também as atribuições formuladas ao Município por intermédio das alterações na Lei ํo 10.257/2001 (Estatuto das Cidades) promovidas pelos artigos 26 e 27 da PNPDEC.

O plano diretor, instrumento básico da política de desenvolvimento e expansão urbana tornou-se obrigatório para as cidades incluídas no cadastro 
nacional de municípios com áreas suscetíveis à ocorrência de deslizamentos de grande impacto, inundações bruscas ou processos geológicos ou hidrológicos correlatos, conforme disposição do inciso VI, do artigo 41 do Estatuto da Cidade.

Os planos diretores das cidades incluídas no cadastro deverão conter o mapeamento contendo as áreas suscetíveis à ocorrência de deslizamentos de grande impacto, inundações bruscas ou processos geológicos ou hidrológicos correlatos e o planejamento de ações de intervenção preventiva e realocação de população de áreas de risco de desastre.

As exigências aos planos diretores das cidades incluídas no cadastro em tela contribuem para a redução dos riscos de desastres naturais por meio do reconhecimento das características do território municipal, do planejamento e implantação de medidas preventivas ou da realocação da população instalada em áreas de risco.

Outra alteração promovida pela Lei 12.608/2012 relaciona-se aos Municípios que pretendam ampliar o seu perímetro urbano após a data de sua publicação, os quais ficarão obrigados a elaborar projeto específico que contenha, no mínimo, entre outras exigências, a delimitação dos trechos com restrições à urbanização e dos trechos sujeitos a controle especial em função de ameaça de desastres naturais.

É notório que o Município foi o ente federativo com maiores atribuições com relação às áreas de risco, o que se pode explicar pela maior proximidade espacial entre essas e a administração municipal. O mapeamento, monitoramento, fiscalização e realocação das populações em áreas de risco são fatores de extrema relevância para a redução dos prejuízos materiais e humanos, ao passo que é nessas áreas que se verificam a maioria desses prejuízos.

\section{A BUSCA DA SUSTENTABILIDADE NA PNPDEC}

A Lei 12.608/2012 instituiu a Política Nacional de Proteção e Defesa Civil e estabeleceu diversas diretrizes para a gestão de desastres naturais no Brasil.

Conforme determina o parágrafo único do artigo 3a a PNPDEC tem o objetivo de promoção do desenvolvimento sustentável.

Revista do Direito da UNISC, Santa Cruz do Sul, v..2, n. 46, p. 63-85, maio - ago. 2015. 
Parágrafo único. A PNPDEC deve integrar-se às políticas de ordenamento territorial, desenvolvimento urbano, saúde, meio ambiente, mudanças climáticas, gestão de recursos hídricos, geologia, infraestrutura, educação, ciência e tecnologia e às demais políticas setoriais, tendo em vista a promoção do desenvolvimento sustentável. (BRASIL, 2012, grifo nosso)

Para alcançar referido desenvolvimento sustentável é necessária a mitigação da vulnerabilidade do meio ambiente humano, entendido este como as áreas urbanas ou rurais ocupadas pelo homem.

Conforme já demonstrado existem ocupações localizadas em áreas especialmente sujeitas a ocorrência de desastres decorrentes do impacto de fenômenos naturais. Tais desastres quando consumados acabam com a sustentabilidade dessas localidades.

As áreas de risco situadas nos centros urbanos receberam especial atenção do diploma em tela, o que se pode aferir das múltiplas modificações inseridas na Lei 10.257/2001 (Estatuto das Cidades) e dos deveres atribuídos aos entes federados já tratados no presente estudo. Resta abordar os dispositivos vinculados à promoção da sustentabilidade nos centros urbanos.

Com relação ao aspecto econômico da sustentabilidade a PNPDEC determina o estímulo à reorganização do setor produtivo e a reestruturação econômica das áreas atingidas por desastres, a fim de proporcionar emprego e renda para os moradores afetados após a recuperação das áreas, o que contribui para a adoção de medidas preventivas por parte dos próprios, como a utilização de materiais de melhor qualidade para a construção das residências e a adoção de medidas estruturais adequadas para a mitigação de futuros riscos.

Há que se mencionar ainda a necessidade dos Planos Diretores dos Municípios incluídos no cadastro nacional de municípios com áreas suscetíveis à ocorrência de deslizamentos de grande impacto, inundações bruscas ou processos geológicos ou hidrológicos correlatos, e daqueles que pretendam ampliar o seu perímetro urbano após a data de publicação da PNPDEC, de definir parâmetros de parcelamento, uso e ocupação do solo, de modo a promover a diversidade de usos e contribuir para a geração de emprego e renda.

Com relação à sustentabilidade ambiental, além do disposto com relação aos aspectos urbanísticos das áreas de risco, que indubitavelmente correspondem à

Revista do Direito da UNISC, Santa Cruz do Sul, v..2, n. 46, p. 63-85, maio - ago. 2015. 
sustentabilidade ambiental, a PNPDEC dispõe sobre a proteção das infraestruturas naturais, relativamente à proteção da vegetação e dos cursos d'água. É o que se depreende do inciso $X$ do artigo 5ํa PNPDEC

Art. $5^{\circ}$ São objetivos da PNPDEC:

$X$ - estimular o ordenamento da ocupação do solo urbano e rural, tendo em vista sua conservação e a proteção da vegetação nativa, dos recursos hídricos e da vida humana; (BRASIL, 2012, grifo nosso)

Também com relação à proteção das infraestruturas naturais, embora não estabelecido pela PNPDEC, mas também integrante do conjunto de normas que regem a gestão de desastres naturais está o inciso $\mathrm{VI}$ do artigo 42-A do Estatuto das Cidades, o qual foi inserido pela Lei no 12.983/2014 e determina a identificação e o estabelecimento de diretrizes para a preservação e ocupação das áreas verdes municipais, quando for o caso, com vistas à redução da impermeabilização das cidades.

Ainda relativamente ao aspecto ambiental da sustentabilidade, porém, concernente à infraestrutura construída, está o inciso IV do artigo 42-A do Estatuto das Cidades, inserido pelo artigo 26 da PNPDEC, que determina que o plano diretor dos Municípios incluídos no cadastro nacional de municípios com áreas suscetíveis à ocorrência de deslizamentos de grande impacto, inundações bruscas ou processos geológicos ou hidrológicos correlatos deverá conter as medidas de drenagem urbana necessárias à prevenção e à mitigação de impactos de desastres.

A drenagem das águas pluviais ocorre não somente pela infiltração nos solos permeáveis, mas também pelo sistema de drenagem artificial (tubulações, galerias, bueiros), instrumento indispensável para a prevenção de enchentes, inundações e alagamentos.

Com relação à sustentabilidade social da PNPDEC indica-se a participação social como o principal fator apontado pelo legislador para o seu alcance.

Em diversos momentos o legislador intencionou provocar uma maior participação social na gestão de desastres naturais o que de fato é indispensável para o sucesso na redução de riscos e mitigação de danos, afinal é a própria população exposta a riscos e danos que tem as melhores condições de intervir 
primeiramente nos contextos de desastres, de fiscalizar com maior intensidade as áreas vulneráveis e, portanto, reconhecer melhor os focos de risco alto e muito alto.

A participação da sociedade civil é prevista no artigo $4^{\circ}$ como uma das diretrizes da PNPDEC, que tem como um de seus objetivos "orientar as comunidades a adotar comportamentos adequados de prevenção e de resposta em situação de desastre e promover a autoproteção". (BRASIL, 2012)

Os Municípios são os principais intermediadores da participação da sociedade na gestão de desastres naturais, visto que cabe a estes "manter a população informada sobre áreas de risco e ocorrência de eventos extremos, bem como sobre protocolos de prevenção e alerta e sobre as ações emergenciais em circunstâncias de desastres; mobilizar e capacitar os radioamadores para atuação na ocorrência de desastre e; estimular a participação de entidades privadas, associações de voluntários, clubes de serviços, organizações não governamentais e associações de classe e comunitárias nas ações do SINPDEC e promover o treinamento de associações de voluntários para atuação conjunta com as comunidades apoiadas". (BRASIL, 2012)

Outro importante fator que deve ser contabilizado no aspecto social da sustentabilidade das áreas de risco é a manutenção da cultura local, proveniente das relações sociais cotidianas que transcorrem nas vilas e morros. Por óbvio que a manutenção da cultura local, de maneira alguma pode ensejar uma exposição daquela população a riscos à sua vida e integridade física, mas quando for possível a adoção de medidas de engenharia que eliminem o risco de desastres, essas devem ser priorizadas com relação à realocação da população.

É importante mencionar que as obras de engenharia que mitiguem os riscos nas áreas de risco devem possuir viabilidade econômica, mas ressalte-se que essa viabilidade não se confunde com menor custo, por exemplo, com relação à realocação. Se a adoção das medidas estruturais e não estruturais forem aptas a dirimir os riscos, há que se adotar um critério de razoabilidade, para avaliar sua viabilidade econômica, considerando-se os custos que seriam necessários para promover a realocação da população daquela comunidade.

Revista do Direito da UNISC, Santa Cruz do Sul, v..2, n. 46, p. 63-85, maio - ago. 2015. 
É notória na PNPDEC e nos demais diplomas que regulamentam a gestão de desastres naturais a busca pela sustentabilidade dos centros urbanos, e principalmente das áreas ambientalmente vulneráveis desses.

Vige, no entanto, ainda a insustentabilidade dessas áreas, o que é demonstrando periodicamente pelos desastres naturais, ocorridos majoritariamente, no caso brasileiro, no período chuvoso.

Os deslizamentos de terra e os óbitos resultantes desses e dos demais fenômenos naturais representam o auge da insustentabilidade desses sistemas, visto que culminam no fim da vida humana, e na destruição total ou parcial de aglomerados.

Vale lembrar que no Brasil, apenas no biênio de 2011/2012 foram registrados 1.187 óbitos o que demonstra a insustentabilidade das áreas de risco do nosso País.

Casos paradigmáticos podem ser citados, como os deslizamentos na região serrana do Rio de Janeiro e do Morro do Bumba em Niterói/RJ.

O caso da região serrana do Rio de Janeiro colocou em xeque a sustentabilidade de todo o território das cidades de Sumidouro e São José do Vale do Rio Preto o que se pode constatar do fato de que nessas cidades $100 \%$ da população foi afetada pelos fenômenos naturais.

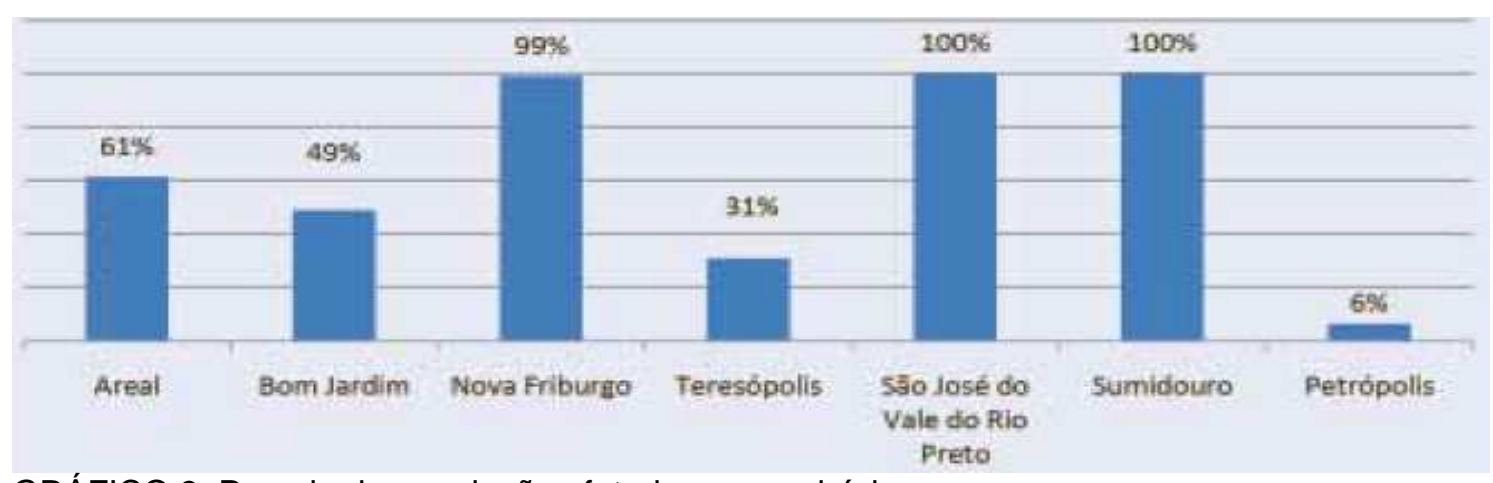

GRÁFICO 3: Parcela da população afetada por município

Fonte: (BANCO MUNDIAL, 2012)

Vale mencionar também que na mesma ocasião foram destruídas mais de 7.900 residências e mais de 6.500 foram danificadas, sendo que $91 \%$ dessas residências pertenciam ao segmento popular. Referido evento foi responsável pelo desabrigamento de 16.458 pessoas e pela morte de 905 pessoas, evidenciando a

Revista do Direito da UNISC, Santa Cruz do Sul, v..2, n. 46, p. 63-85, maio-ago. 2015. 
insustentabilidade das cidades afetadas e a necessidade de modificar o cenário existente.

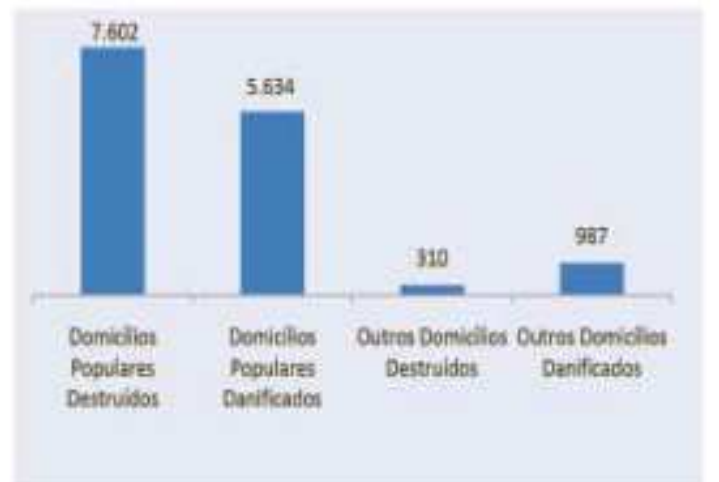

Gráfico 4 - Domicílios destruídos e danificados Fonte: (Banco Mundial, 2012)

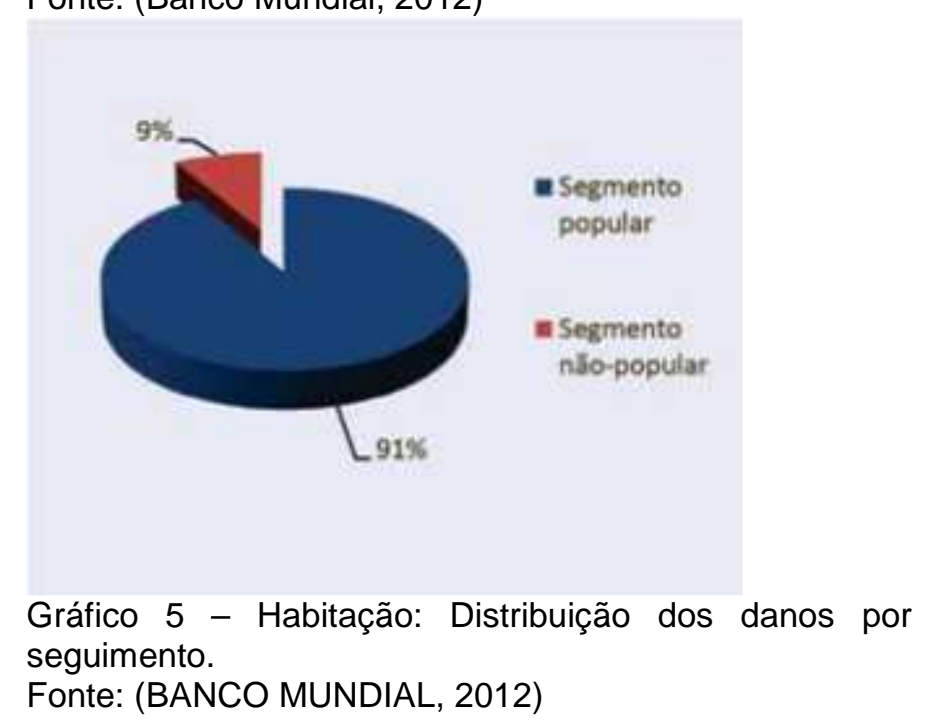

A PNPDEC sancionada seis meses após os desastres da região serrana fluminense, objetiva por intermédio dos mecanismos propostos, promover a sustentabilidade dos centros urbanos e consequentemente evitar ou minimizar a ocorrência dos supramencionados danos materiais e humanos.

Nesse aspecto é indispensável abordar o dever de realocar as populações residentes em áreas de alto risco ou em áreas irrecuperáveis.

Art. $5^{\circ}$ São objetivos da PNPDEC:

$\mathrm{XI}$ - combater a ocupação de áreas ambientalmente vulneráveis e de risco e promover a realocação da população residente nessas áreas;

Art. $8^{\circ}$ Compete aos Municípios:

Revista do Direito da UNISC, Santa Cruz do Sul, v..2, n. 46, p. 63-85, maio-ago. 2015. 


\begin{abstract}
VII - vistoriar edificações e áreas de risco e promover, quando for o caso, a intervenção preventiva e a evacuação da população das áreas de alto risco ou das edificações vulneráveis;

Art. 42-A. Além do conteúdo previsto no art. 42, o plano diretor dos Municípios incluídos no cadastro nacional de municípios com áreas suscetíveis à ocorrência de deslizamentos de grande impacto, inundações bruscas ou processos geológicos ou hidrológicos correlatos deverá conter: III - planejamento de ações de intervenção preventiva e realocação de população de áreas de risco de desastre; (inserido pelo artigo 26 da Lei no 12.608 de 10 de Abril de 2012) (BRASIL, 2012, grifo nosso)
\end{abstract}

A realocação da população residente em áreas de risco pode ser considerada a última medida visando o alcance da sustentabilidade dos centros urbanos. O reconhecimento de que algumas áreas são impróprias para a habitação humana e por vezes irrecuperáveis para tal, mesmo com a adoção de medidas estruturais, é indispensável para que se previnam futuros desastres. Admitir a insustentabilidade de algumas localidades é essencial para se promover a sustentabilidade da cidade como um todo, e afinal o grande objetivo da PNPDEC é "estimular o desenvolvimento de cidades resilientes e os processos sustentáveis de urbanização", conforme determinado pelo inciso VI do seu artigo $5^{\circ}$.

\title{
5 CONCLUSÃO
}

A Lei $12.608 / 2012$ e os demais diplomas que regulamentam a gestão de desastres no Brasil, principalmente a Lei ํo 10.257/2001 objetivam promover a sustentabilidade das áreas de risco, a fim de propiciar à população residente nessas localidades, a manutenção de seus laços culturais e o gozo dos direitos fundamentais à vida, a integridade física e à moradia. As favelas do Brasil sempre foram berço de uma cultura rica e variada, demonstrada através da música, da dança e da moda. Proporcionar emprego e renda e condições salubres de moradia nessas localidades que estiveram expostas a riscos de desastres naturais permitiriam a perenização de uma cultura, que deve ser objeto de respeito e de esforços do Estado.

Ocorre que por vezes a vulnerabilidade das áreas de risco é tamanha que a adoção de medidas estruturais não é suficiente para propiciar o uso habitacional seguro, razão pela qual, em casos mais graves se faz necessária a realocação da população dessas localidades para outros bairros.

Revista do Direito da UNISC, Santa Cruz do Sul, v..2, n. 46, p. 63-85, maio - ago. 2015. 
Não obstante a PNPDEC vise promover a sustentabilidade nas áreas de risco por meio de medidas preventivas estruturais, de participação social e de geração de emprego e renda, o reconhecimento da insustentabilidade de algumas áreas é primordial para a promoção de cidades resilientes e sustentáveis, ao passo que ao evacuar as áreas de alto risco evita-se a concretização de futuros danos e oferta-se maior segurança a população.

\section{REFERÊNCIAS}

BANCO MUNDIAL. Avaliação de Perdas e Danos: Inundações e Deslizamentos na Região Serrana do Rio de Janeiro - Janeiro de 2011. Brasília: Editora Executiva, 2012.

BRASIL. Decreto 7.257, de 4 de Agosto de 2010. Regulamenta a Medida Provisória no 494 de 2 de julho de 2010, para dispor sobre o Sistema Nacional de Defesa Civil - SINDEC, sobre o reconhecimento de situação de emergência e estado de calamidade pública, sobre as transferências de recursos para ações de socorro, assistência às vítimas, restabelecimento de serviços essenciais e reconstrução nas áreas atingidas por desastre, e dá outras providências. Diário Oficial, 06 ago 2010

BRASIL. Lei 10.257, de 10 de Julho de 2001. Regulamenta os arts. 182 e 183 da Constituição Federal, estabelece diretrizes gerais da política urbana e dá outras providências. Diário Oficial, Brasília, 11 jul. 2001.

BRASIL. Lei 12.608, de 10 de Abril de 2012. Institui a Política Nacional de Proteção e Defesa Civil - PNPDEC; dispõe sobre o Sistema Nacional de Proteção e Defesa Civil - SINPDEC e o Conselho Nacional de Proteção e Defesa Civil - CONPDEC; autoriza a criação de sistema de informações e monitoramento de desastres; altera as Leis $\mathrm{n}^{\text {os }} 12.340$, de $1^{\circ}$ de dezembro de 2010, 10.257, de 10 de julho de 2001 , 6.766, de 19 de dezembro de 1979, 8.239, de 4 de outubro de 1991, e 9.394, de 20 de dezembro de 1996; e dá outras providências. Diário Oficial, Brasília, 11 abr. 2012.

BRASIL. Ministério da Integração Nacional. Secretaria Nacional de Defesa Civil. Centro Nacional de Gerenciamento de Riscos e Desastres. Anuário brasileiro de desastres naturais: 2011 / Centro Nacional de Gerenciamento de Riscos e Desastres. - Brasília: CENAD, 2012.

BRASIL. Ministério da Integração Nacional. Secretaria Nacional de Defesa Civil. Centro Nacional de Gerenciamento de Riscos e Desastres. Anuário brasileiro de desastres naturais: 2012 / Centro Nacional de Gerenciamento de Riscos e Desastres. - Brasília: CENAD, 2013.

Revista do Direito da UNISC, Santa Cruz do Sul, v..2, n. 46, p. 63-85, maio - ago. 2015. 
BRASIL. Ministério das Minas e Energia. Secretaria de Geologia, Mineração e Transformação Mineral. Serviço Geológico do Brasil - CPRM. Departamento de Gestão Territorial - DEGET. Ação Emergencial para Delimitação de Áreas em Alto e Muito Alto Risco a Enchentes e Movimentos de Massa em Betim - Minas Gerais. 2012.

BRASIL. Ministério da Ciência e Tecnologia. Instituto Nacional de Pesquisas Espaciais - INPE. Desastres Naturais e Geotecnologias: Conceitos Básicos. Versão preliminar. Santa Maria, 2007.

CADERNOS MCIDADES/DES. URBANO. Política Nacional de Desenvolvimento Urbano 1. Brasília, Novembro de 2004.

CARVALHO, Delton Winter de; DAMASCENA, Fernanda Libera. Direito dos Desastres. Porto Alegre: Livraria do Advogado, 2013.

CONDE, Luiz Paulo. Cadernos de Ciência, São Paulo: FINEP, n. 28, p.13-15, jul./ago./set. 1992.

NOLASCO, Noreci Gottscalk. Direito Fundamental à Moradia. São Paulo: Editora Pillares, 2008.

PAZZINI, Wrana Maria. Entre Cidade e Estado, a propriedade e seus direitos. Revista de Estudos Regionais e Urbanos, ano IX, no 26, p. 84-90, 1989.

RELATÓRIO Brundtland 1987. Disponível em:

<http://www.un.org/documents/ga/res/42/ares42-187.htm>. Acesso 10/09/2014.

RIBEIRO, Luiz César Queiroz. Dinâmica socioterritorial das metrópoles brasileiras: dispersão e concentração. In: Boletim de IPEA - Políticas Sociais Acompanhamento e Análise n. 12. Brasília: Instituto de Pesquisas Econômicas Aplicadas, fevereiro de 2006, p.221-229.

RIO DE JANEIRO, Universidade Federal Rural do (UFRRJ). Mapa mental dos problemas das enchentes urbanas. Disponível em

<http://www.ufrrj.br/institutos/it/de/acidentes/mma10.htm>. Acesso em 28 jul 2014.

ROLNIK, Raquel. A cidade e a lei: legislação, política urbana e territórios na cidade de São Paulo. São Paulo: Studio Nobel: FAPESP, 1997.

SANTOS, Milton. A Urbanização Brasileira. 5. ed. São Paulo: Editora da Universidade de São Paulo, 2005.

VEIGA, José Eli da. Desenvolvimento Sustentável: o desafio do século XXI. 3. ed. Rio de Janeiro: Garamond, 2008.

Revista do Direito da UNISC, Santa Cruz do Sul, v..2, n. 46, p. 63-85, maio - ago. 2015. 